\title{
JPEB
}

Jurnal Penelitian Ekonomi dan Bisnis, 4 (2), 2019, Hal: 143-152

http://www.jpeb.dinus.ac.id

\section{MINIMASI BIAYA PRODUKSI PADA PRODUK WINKER RELAY MELALUI PERENCANAAN PRODUKSI AGREGAT}

\author{
Yevita Nursyanti \\ Program Studi Manajemen Logistik Industri Elektronika, Politeknik APP Jakarta \\ Jalan Timbul No 34 Jakarta, Indonesia \\ *Corresponding Email : yevita.nursyanti@gmail.com
}

Diterima: Mei 2019; Direvisi: Agustus 2019; Dipublikasikan: September 2019

\begin{abstract}
The purpose of this research is to determine demand forecasting on relay winker products and to determine the aggregate planning of relay winker products that produce minimum costs. The method used in this study is a comparative quantitative method. The data used in conducting aggregate planning are data from forecasting calculations with the chosen method, forecasting is calculated using several methods, namely the Moving Average, Exponential Smoothing, Double Exponential Smoothing, Quadratic and Linear Regression methods. Select this method by looking for the MAPE value. The method that has the smallest MAPE value is Double exponential Smoothing with a value of 2.7\%. Aggregate production planning is carried out for 2017 with the method of transportation (least cost), permanent labor and level strategy. The results of data processing show the best method for aggregate planning is transportation method (least cost) which has the lowest cost of Rp. $9,858,625,445$.
\end{abstract}

Keywords: Service and Quality;Aggregate Planning;Demand Forecasting

\begin{abstract}
ABSTRAK
Tujuan penelitian ini adalah untuk menentukan peramalan permintaan pada produk winker relay dan untuk menentukan perencanaan agregat produk winker relay yang menghasilkan biaya minimum. Metode yang digunakan dalam penelitian ini adalah metode kuantitatif komparatif. Data yang digunakan dalam melakukan perencanaan agregat adalah data hasil perhitungan peramalan dengan metode yang terpilih, peramalan dihitung dengan menggunakan beberapa metode yaitu metode Moving average, Exponential Smoothing, Double exponential Smoothing, Kuadratik dan Regresi Linier. Pemilihan metode ini dengan mencari nilai MAPE. Metode yang memiliki nilai MAPE terkecil adalah Double exponential Smoothing dengan nilai sebesar 2,7\%. Perencanaan produksi agregat dilakukan untuk tahun 2017 dengan metode transportasi (least cost), tenaga kerja tetap dan level strategy. Hasil pengolahan data menunjukan metode yang terbaik adalah metode transportasi (least cost) yang memiliki biaya terendah sebesar Rp. 9.858.625.445.
\end{abstract}

Kata Kunci: Layanan dan Kualitas; Perencanaan Agregat; Peramalan Permintaan 


\section{PENDAHULUAN}

Jumlah produksi biasanya dipengaruhi oleh jumlah permintaan yang diminta oleh pasar dan konsumen. Tidak sesuainya jumlah produksi yang dilakukan oleh perusahaan dengan jumlah permintaan yang diminta oleh pasar dan konsumen, dapat menyebabkan penumpukan persediaan barang jadi di gudang perusahaan yang bisa berdampak pada tingginya biaya penyimpanan barang jadi yang harus dibayarkan oleh perusahaan setiap periodenya dan atau dapat pula menyebabkan kerugian bagi perusahaan dalam bentuk hilangnya pendapatan akibat hilangnya permintaan dari konsumen yang tidak dapat terpenuhi oleh perusahaan.

Sehingga untuk mengatasi masalah tersebut peramalan menjadi tahap penting untuk melakukan perencanaan produksi. Kemudian perlu dilakukannya perencanaan agregat bagi perusahaan untuk menyesuaikan jumlah permintaan dengan kapasitas produksi yag dimiliki sehingga dapat meminimumkan kerugian yang ditanggung oleh perusahaan yang bisa berupa tingginya biaya penyimpanan barang jadi atau hilangnya pendapatan akibat perusahaan tidak mampu menjual hasil kelebihan produksi yang tidak diminta oleh konsumen.

Perusahaan harus tepat dalam memperkirakan jumlah bahan baku yang akan dipesan agar tidak terjadi kekurangan atau kelebihan bahan baku. Selain itu, ketika telah menerima order dari konsumen perusahaan belum meninjau terlebih dahulu sumber daya kapasitas produksi yang tersedia. Dalam melakukan perencanaan produksi, Perusahaan belum menyesuaikan dengan kondisi dan kapasitas produksi yang dimiliki. Hal tersebut memperlihatkan bahwa perusahaan belum memperhitungkan perbandingan antara kapasitas yang dibutuhkan dengan kapasitas yang tersedia dalam menentukan jumlah produksi yang optimal untuk mencapai keuntungan yang maksimal. Hal ini dapat mengakibatkan banyaknya kelebihan produk dan pengeluaran biaya yang lebih besar dan dapat menyebabkan kerugian terhadap perusahaan. Berikut ini merupakan grafik pencapaian produksi Winker Relay 2016:

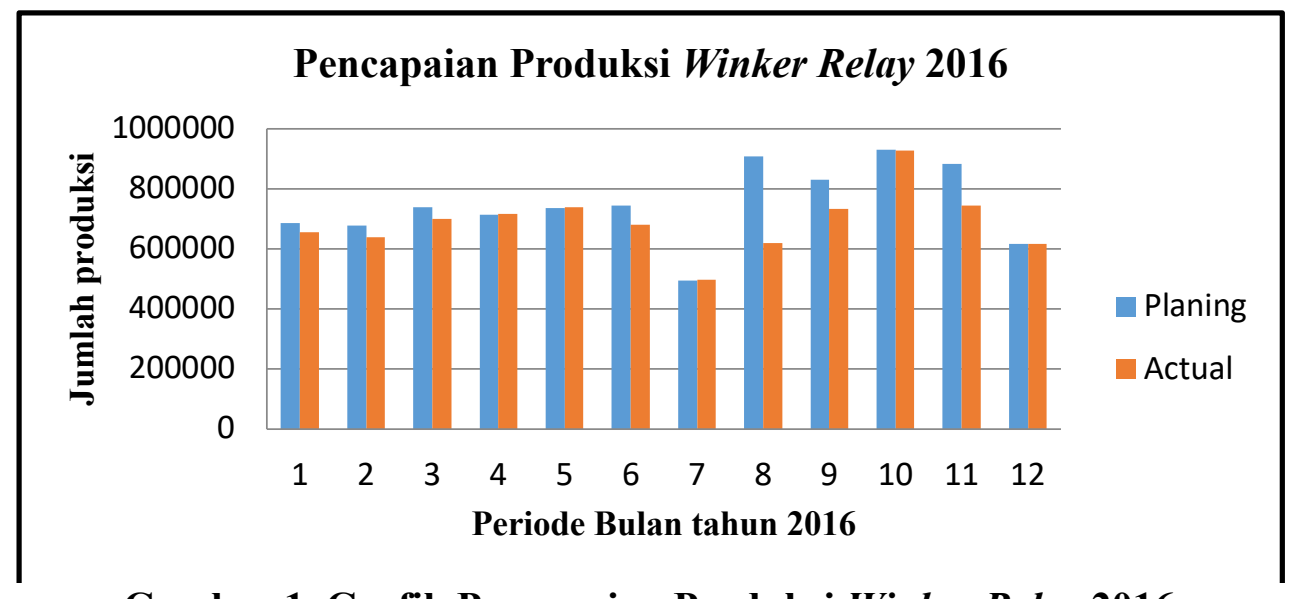

Gambar 1. Grafik Pencapaian Produksi Winker Relay 2016

Dari grafik diatas menunjukkan bahwa pencapaian produksi aktual yang dihasilkan hanya $93,19 \%$ sedangkan target perusahaan adalah $100 \%$. Oleh sebab itu, dibutuhkan suatu perencanaan produksi dengan metode yang digunakan adalah perencanaan agregat yang dapat menjadwalkan kebutuhan produk Winker relay. Dengan merencanakan kebutuhan produksi, diharapkan dapat menghindari kelebihan produksi yang menyebabkan kerugian bagi perusahaan. Berdasarkan masalah yang telah dirumuskan sebelumnya, maka tujuan penelitian adalah untuk menentukan peramalan permintaan pada produk winker relay serta menentukan perencanaan agregat produk winker relay yang menghasilkan biaya minimum. 


\section{TINJAUAN PUSTAKA}

Menurut Heizer dan Render (2009) tujuan perencanaan agregat adalah untuk memenuhi permintaan atas perkiraan masa depan dan meminimalkan biaya selama periode perencanaan. Namun, banyak hal yang perlu diperhatikan mungkin jauh lebih penting daripada biaya yang rendah. Strategi ini mungkin untuk kelancaran tingkat kerja, menurunkan tingkat persediaan, dan untuk memenuhi permintaan pelanggan dengan tingkat layanan yang lebih baik. Menurut Schroeder (2003) tujuan dari perencanaan agregat adalah untuk membuat tingkat output secara keseluruhan untuk kebutuhan permintaan di masa depan yang berfluktuasi. Perencanaan agregat dihubungkan dengan keputusan bisnis lainnya seperti keuangan, pemasaran, dan sumber daya manusia. Tujuan dari perencanaan agregat adalah menentukan kombinasi yang optimal dari tingkat produksi, jumlah tenaga kerja, dan tingkat persediaan. Perencanaan agregat yang tergolong perencanaan jangka menengah memegang peranan penting dalam perencanaan operasi secara kesuluruhan.

Penggunakaan kata agregat menunjukan bahwa perencanaan ditunjukan bahwa perencanaan dilakukan di tingkat kasar dan dimaksudkan untuk memenuhi kebutuhan total seluruh produk dengan menggunakan seluruh sumber daya manusia dan peralatan yang ada pada fasilitas produksi tersebut.Peramalan merupakan suatu keputusan tentang kemungkinan masa yang akan datang yang didasarkan fakta-fakta ekonomi sekarang dan sejarah masa lalu. Dalam proses produksi peramalan digunakan untuk menentukan jumlah permintaan konsumen terhadap suatu produk, Alfarisi (2017).

Metode peramalan time series terdiri dari beberapa metode, salah satunya adalah metode moving average. Metode moving average menggunakan data - data historis untuk menentukan peramalan permintaan pada periode berikutnya. Metode moving average dapat menggunakan perhitungan rata - rata untuk dua bulan, tiga bulan, empat bulan, bergantung pada ketentuan yang akan digunakan perusahaan. Metode moving average digunakan jika data masa lalu tidak memiliki unsur trend atau faktor musiman. Tujuan dari penggunaan moving average adalah untuk mengurangi acakan dalam deret waktu, Nurlifa (2017).

Pada penggunaan metode moving average dua bulan, perhitungan mencakup rata- rata dua bulan dari data permintaan historis untuk menentukan jumlah permintaan periode selanjutnya dari hasil peramalan. Semakin panjang jangka waktu moving average, semakin terlihat dalam ramalan atau menghasilkan moving average yang semakin halus, Rachman (2018).Metode peramalan time series lainnya adalah Simple Exponential Smoothing (SES). Pola data yang fluktuatif dan bergejolak umumnya menggunakan model Simple Exponential Smoothing. Metode Simple Exponential Smoothing lebih cocok digunakan untuk meramalkan hal-hal yang fluktuasinya secara acak (tidak teratur).Metode Double Exponential Smoothing, metode ini merupakan pengembangan dari Single Exponential Smoothingdimana menambahkan unsur trend pada bobot perhitungan, sehingga pada Double Exponential Smoothing (Metode Holt) kita memberikan dua jenis bobot pada perhitungan yaitu level $(\alpha)$ dan trend $(\beta)$. Peramalan Penghalusan Eksponensial (Exponential Smoothing) merupakan salah satu kategori metodetime series yang menggunakan pembobotan data masa lalu untuk melakukan peramalan. Metode peramalan selanjutnya adalah model regresi linier. Regresi linier merupakan metode statistik yang bertujuan untuk membentuk model antara variabel dependen (Y) dengan variabel independen (X), Tannady (2013).

Regresi linier sederhana dipergunakan untuk mrngrtahui pengaruh satu buah variabel bebas dengan satu buah variabel terikat. Langkah-langkah yang dilakukan untuk menyelesaikan kasus menggunakan regresi linier adalah sebagai berikut, Renyaan (2018).

1. Tentukan $\mathrm{Y}=$ variabel tak bebas, dan $\mathrm{X}=$ variabel bebas

2. Hitung nilai $a$ dan $b$ 


$$
\begin{gathered}
\mathrm{b}=\frac{{ }^{\mathrm{n}} \sum^{\mathrm{xy}}-\sum^{\mathrm{x}} \sum^{\mathrm{y}} \mathrm{n}}{\sum \mathrm{x}^{2}-\left(\sum \mathrm{x}\right)^{2}} \\
\mathrm{a}=\mathrm{y}-\mathrm{bx}
\end{gathered}
$$

3. Setelah nilai a dan $\mathrm{b}$ sudah ditemukan, masukan nilai tersebut dalam rumus persamaan.

$$
\mathrm{Y}=\mathrm{a}+\mathrm{bx}
$$

Perencanaan agregat dengan metode transportasi digunakan untuk membuat perencanaan minimasi biaya pengiriman dari tempat asal ke tempat tujuan. Perencanaan agregat menggunakan metode transportasi merupakan bagian dari perencanaan produksi program linear dengan jumlah tenaga kerja yang tetap. Penggunaan metode transportasi dapat berupa reguler, overtime, subkontrak, backorder dan inventory. Sebelum menggunakan model transpotasi terdapat beberapa informasi penting yang perlu diketahui agar metode ini dapat diaplikasikan, yaitu dengan: Nasution(2008).

1. Kapasitas tersedia (supply) dapat dinyatakan dalam unit yang sama dengan kebutuhan (demand).

2. Total kapasitas untuk horizon waktu perencanaan harus sama dengan total peramalan kebutuhan, apabila tidak sama, kita dapat menggunakan variable bayangan (dummy) sebanyak jumlah selisih tersebut dengan unit cost $=0$ (nol).

3. Semua hubungan biaya merupakan hubungan linear.

4. Hitung terlebih dahulu dari total permintaan seluruh produk selama horizon perencanaan dalam satuan agregat kemudian masukkan ke dalam kolom ketiga.

5. Lalu hitung dahulu kapasitas yang tersedia untuk setiap pilihan produksi selama horizon perencanaan dalam satuan agregat dan masukkan ke dalam baris ketiga.

6. Hitung ongkos per unit satuan agregat sebagai akibat dari pilihan strategi produksi yang telah diterapkan dan masukkan kedalam sel-sel ditengah tabel transportasi.

7. Optimasikan rencana produksi disetiap periode dalam horizon perencanaan mulai dari periode paling awal sampai ke periode paling akhir. Dan usahakan menggunakan kapasitas produksi sel dengan ongkos produksi termurah agar seluruh permintaan dapat dipenuhi tepat waktu tanpa adanya pembatalan pesanan atau penundaan pengiriman, kemungkinan konsumen akan beralih pada produk sejenis dari perusahaan kompetitor.

Metode Double Exponential Smoothing salah satu metode peramalan yang digunakan saat pola permintaan historis berfluktuasi dan memiliki trend (kecenderungan naik atau turun). MetodeDouble Exponential Smoothing diperkenalkan oleh C. C. Holt pada sekitar tahun 1958. Metode ini, digunakan untuk menghilangkan trend kecenderungan data permintaan, Perdana (2014).

Langkah yang dilakukan untuk menggunakan metode Double Exponential Smoothing sebagai berikut : menghitung single moving average, menghitung double moving average, menentukan nilai konstanta, menentukan koefisien trend, menentukan besar nilai peramalan, Hudiyanti (2019).

\section{METODE PENELITIAN}

\section{Observasi}

Berikut merupakan langkah-langkah yang dilakukan dalam peneltian :

Observasi dilakukan dengan peninjauan langsung di seksi PPC (Production Planning Control) dan Factory G di PT. Mitsuba Indonesia untuk melihat alur proses penerimaan permintaan produk, perencanaan bahan baku maupun jadwal induk produksi dan proses produksi awal hingga terbentuknya produk jadi. 


\section{Dokumentasi (Data Sekunder)}

Pengumpulan data seperti data terkait dengan jumlah permintaan barang serta data lain yang diperlukan diperoleh melalui dokumen-dokumen atau catatan dari PT. Mitsuba Indonesia. Data yang telah diperoleh selanjutnya akan di analisis dan digunakan untuk penyelesaian pada bagian hasil dan pembahasan menggunakan metode yang telah ditentukan.

\section{HASIL DAN PEMBAHASAN}

Berdasarkan hasil analisis pola data tersebut maka akan dilakukan perhitungan menggunakan metode peramalan yang tepat. Metode peramalan yang dipilih untuk digunakan adalah metode Moving average, Exponential Smoothing, Double exponential Smoothing, Regresi Linier dan Kuadratik. Berikut ini adalah hasil perhitungan peramalan permintaan produk Winker relay menggunakan metode Moving average, Exponential Smoothing, Double exponential Smoothing, Regresi Linier dan kuadratik.

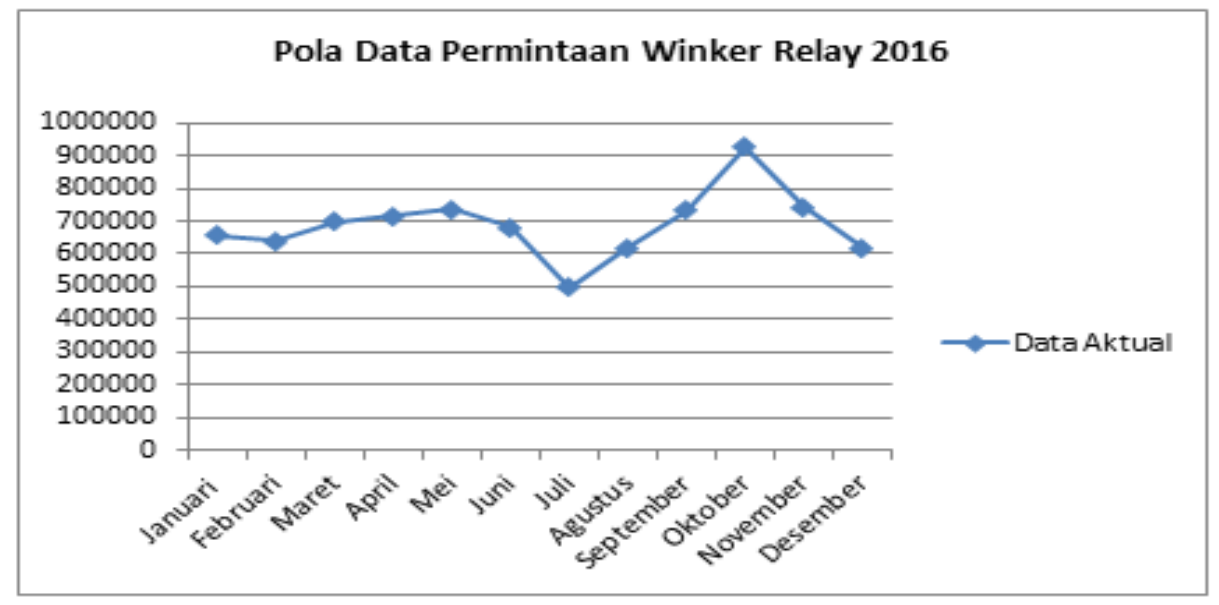

Gambar 2. Grafik Pola Data Permintaan Winker relay 2016

Tabel 1. Perbandingan Hasil Peramalan Winker relay

\begin{tabular}{clc}
\hline No & \multicolumn{1}{c}{ Metode } & MAPE \\
\hline 1 & Moving average 2 bulan & $17,3 \%$ \\
\hline 2 & Moving average 3 bulan & $17,6 \%$ \\
\hline 3 & Moving average 4 bulan & $18,9 \%$ \\
\hline 4 & Simple exponential smoothing & $10,9 \%$ \\
\hline 5 & Double exponential Smoothing & $2,7 \%$ \\
\hline 6 & Regresi Linier & $10,2 \%$ \\
\hline 7 & Kuadratik & $10,3 \%$ \\
\hline
\end{tabular}

Dari hasil perhitungan yang telah dilakukan dengan metode diatas, maka akan dipilih metode yang mempunyai nilai MAPE terkecil. Metode yang dipilih adalah metode, Double exponential Smoothing $\alpha=0,4$. 
Tabel 2. Tabel Perhitungan Perhitungan $S_{t}, S^{\prime}, a_{t}, b_{t}$

\begin{tabular}{ccccccccc}
\hline Bulan & $\mathbf{t}$ & $\mathbf{Y t}$ & $\mathbf{s t}$ & $\mathbf{s}^{\prime} \mathbf{t}$ & $\mathbf{s t - s} \mathbf{t}$ & $\mathbf{a}$ & $\mathbf{B}$ & $\mathbf{Y}^{\prime} \mathbf{t}$ \\
\hline Januari & 1 & 655.811 & 655.811 & 655.811 & & 655.811 & 0 & 655.811 \\
\hline Februari & 2 & 638.176 & 48.757 & 652.989 & $-4.232,40$ & 644.525 & $-2.821,60$ & 641.703 \\
\hline Maret & 3 & 699.725 & 662.796 & 648.024 & $14.771,76$ & 677.567 & $9.847,84$ & $687.415,20$ \\
\hline April & 4 & 716.521 & 706.443 & 702.412 & $4.031,04$ & 710.474 & $2.687,36$ & $713.161,80$ \\
\hline Mei & 5 & 737.753 & 725.014 & 719.918 & $5.095,68$ & 710.474 & $2.687,36$ & $733.506,60$ \\
\hline Juni & 6 & 681.726 & 715.342 & 728.789 & $-13.446,48$ & 730.109 & $-8.964,32$ & $692.931,40$ \\
\hline Juli & 7 & 497.531 & 608.048 & 652.255 & $-44.206,80$ & 701,896 & $-2,94712$ & 534.370 \\
\hline Agustus & 8 & 620.241 & 546.615 & 517.165 & $29.450,40$ & 563.841 & $19.663,60$ & 595.699 \\
\hline September & 9 & 733.990 & 665.741 & 638.441 & $27.299,76$ & 576.065 & $18.199,84$ & $711.240,20$ \\
\hline Oktober & 10 & 927.528 & 811.405 & 764.956 & $46.449,12$ & 857.854 & $30.966,08$ & $888.820,40$ \\
\hline November & 11 & 744.088 & 854.152 & 898.178 & $-44.025,60$ & 810.126 & $-29.350,40$ & 780.776 \\
\hline Desember & 12 & 618.070 & 693.681 & 723.925 & $-30.244,32$ & 663.436 & $-20.162,88$ & $643.273,60$ \\
\hline
\end{tabular}

Dari hasil tracking signal diperoleh nilai-nilaiuntuk model Double Eksponential Smoothing $\alpha=0,4$ berada didalam batas-batas yang dapat diterima (maksimum \pm 4 ), dimana nilai-nilai Tracking signalitu bergerak dari $-3,10$ samai $+3,50$. Hal ini menunjukan bahwa akurasi dari model peramalan Double exponential Smoothing $\alpha=0,4$ dapat diandalkan.

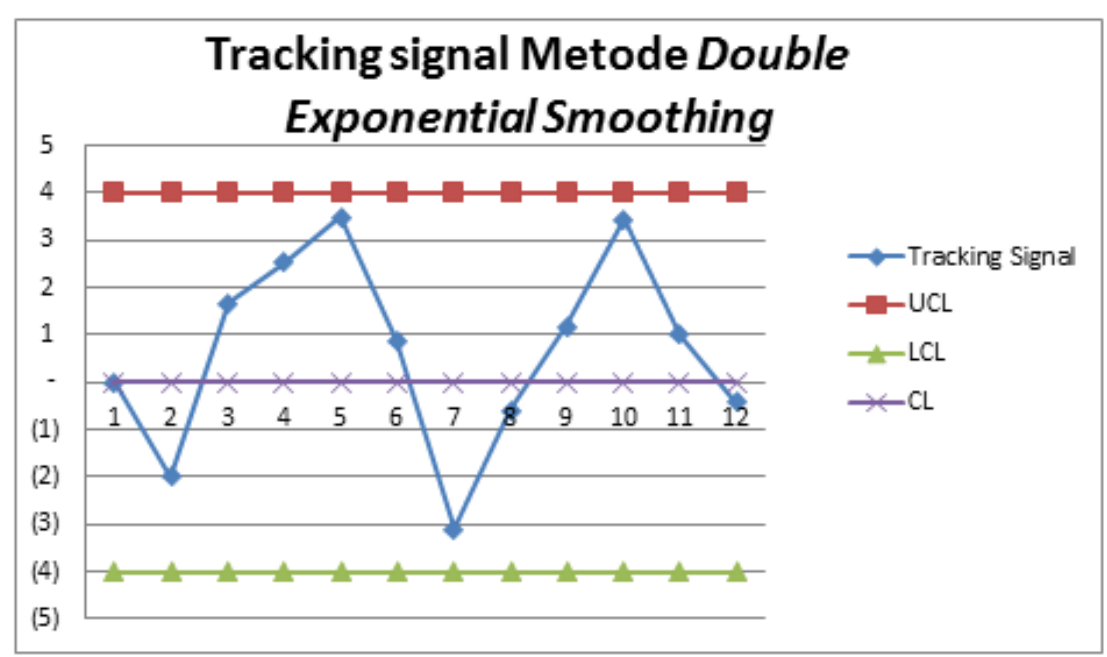

Gambar 3. Grafik Tracking signal Metode Double exponential Smoothing $\alpha=0,4$

Tabel 3. Hasil Peramalan

\begin{tabular}{cccc}
\hline Tahun & Periode & Bulan & $\begin{array}{c}\text { Hasil } \\
\text { Peramalan }\end{array}$ \\
\hline $\mathbf{2 0 1 7}$ & 1 & Januari & 655.811 \\
\cline { 2 - 4 } & 2 & Februari & 641.703 \\
\cline { 2 - 3 } & Maret & 687.415 \\
\cline { 2 - 3 } & 4 & April & 713.162 \\
\hline 5 & Mei & 733.507 \\
\hline 6 & Juni & 692.931 \\
\hline 7 & Juli & 534.370 \\
\hline 8 & Agustus & 595.699 \\
\hline
\end{tabular}




\begin{tabular}{ccc}
\hline 9 & September & 711.240 \\
\hline 10 & Oktober & 888.820 \\
\hline 11 & November & 780.776 \\
\hline 12 & Desember & 643.274 \\
\hline Total & & $\mathbf{8 . 2 7 8 . 7 0 8}$ \\
\hline
\end{tabular}

\section{Perencanaan Agregat}

Selanjutnya adalah penentuan perencanaan agregat menggunakan metode transportasi, metode tenaga kerja tetap dan level strategy. Berikut merupakan tabel hasil peramalan Winker relay dengan metode Double Exponential Smooting :

\section{Metode Transportasi (Least cost)}

Dari metode yang telah dihitung maka hasil dengan nilai total ongkos produksi yang terkecil adalah menggunakan metode Transportasi. Metode Transportasi merupakan salah satu metode yang dapat digunakan untuk menunjang total biaya produksi dari rencana agregat. Perhitungan total biaya produksi dengan metode ini melalui beberapa tahapan. Tahap awal pada metode ini adalah menghitung kapasitas tersedia pada Regular time (RT) dan kapasitas tersedia pada Overtime (OT) atau waktu lembur. Berikut adalah perhitungan untuk Kapasitas RT dan Kapasitas OT :

Tabel 4. Perhitungan Kapasitas Metode Transportasi

\begin{tabular}{ccccc}
\hline Periode & $\begin{array}{c}\text { Kebutuhan } \\
\text { Produksi (Unit) }\end{array}$ & $\begin{array}{c}\text { Hari } \\
\text { Kerja }\end{array}$ & $\begin{array}{c}\text { Kapasitas } \\
\text { Produksi } \\
\text { Normal(Unit/Bul } \\
\text { an) }\end{array}$ & $\begin{array}{c}\text { Kapasitas Produksi } \\
\text { Lembur } \\
\text { (unit/Bulan) }\end{array}$ \\
\hline 1 & 658.342 & 22 & 503.418 & 188.782 \\
\hline 2 & 703.342 & 22 & 503.418 & 188.782 \\
\hline 3 & 694.518 & 24 & 549.184 & 205.944 \\
\hline 4 & 777.376 & 22 & 503.418 & 188.782 \\
\hline 5 & 742.643 & 23 & 526.301 & 197.363 \\
\hline 6 & 753.088 & 23 & 526.301 & 197.363 \\
\hline 7 & 527.651 & 22 & 503.418 & 188.782 \\
\hline 8 & 655.269 & 23 & 526.301 & 197.363 \\
\hline 9 & 722.794 & 23 & 526.301 & 197.363 \\
\hline 10 & 966.148 & 22 & 503.418 & 188.782 \\
\hline 11 & 781.526 & 23 & 526.301 & 197.363 \\
\hline 12 & 706.851 & 23 & 526.301 & 197.363 \\
\hline Total & 8.689 .548 & 272 & 6.224 .083 & 2.334 .031 \\
\hline
\end{tabular}

Berdasarkan tabel diatas nilai kapasitas produksi normal dan kapasitas produksi lembur setiap bulannya yang akan digunakan dalam perhitungan perencanaan agregat mengguakan metode transportasi berbeda-beda disetiap periodenya. 


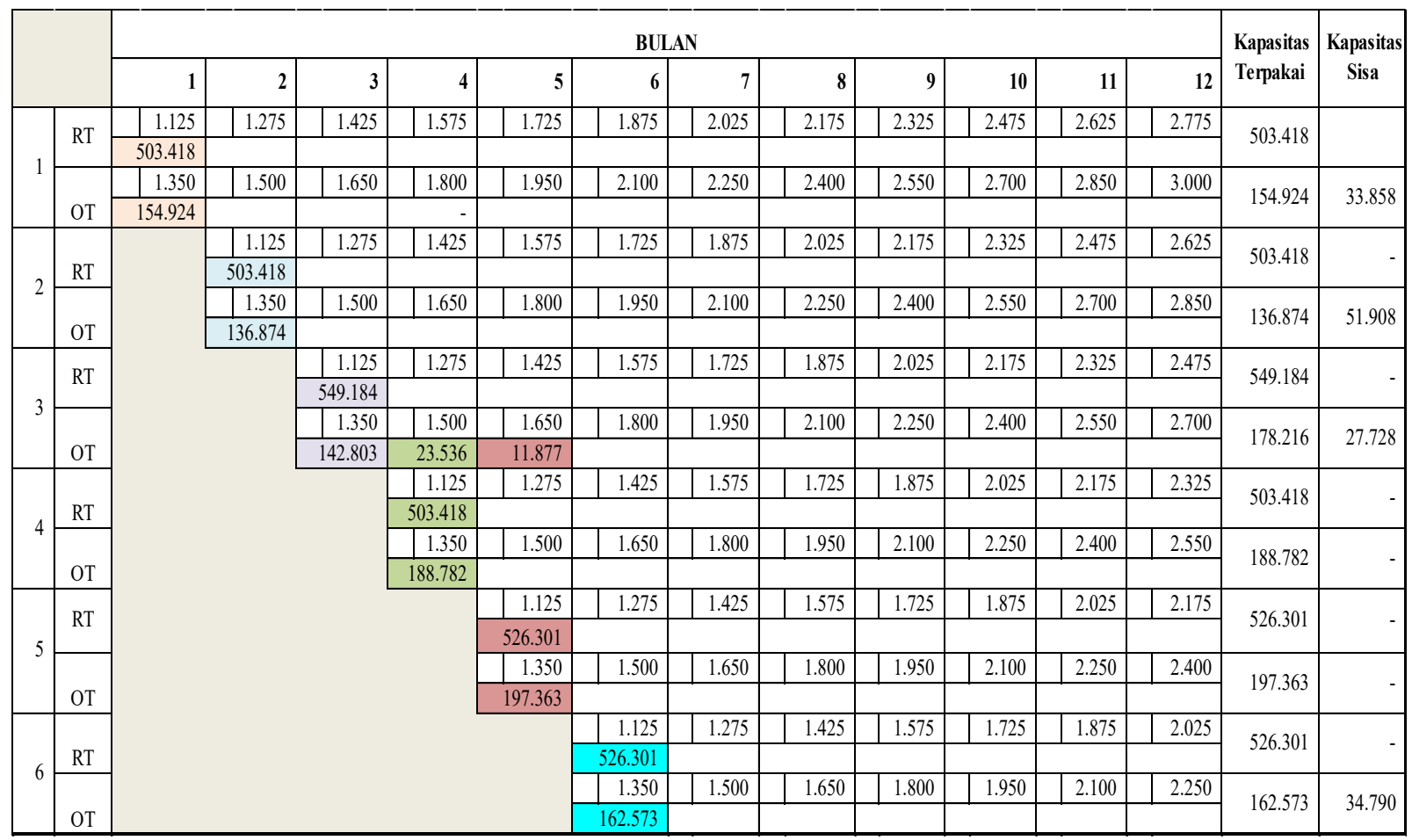

Gambar 4. Matriks Perhitungan Metode Transportasi (Least cost)

\begin{tabular}{|c|c|c|c|c|c|c|c|c|c|c|c|c|c|c|c|}
\hline & \multicolumn{12}{|c|}{ BULAN } & \multirow{2}{*}{$\begin{array}{l}\text { Kapasitas } \\
\text { Terpakai }\end{array}$} & \multirow{2}{*}{$\begin{array}{l}\text { Kapasitas } \\
\text { Sisa }\end{array}$} \\
\hline & & 1 & 2 & 3 & 4 & 5 & 6 & 7 & 8 & 9 & 10 & 11 & 12 & & \\
\hline \multirow{4}{*}{7} & \multirow{2}{*}{ RT } & & & & & & & 1.125 & 1.275 & 1.425 & 1.575 & 1.725 & 1.875 & \multirow{2}{*}{503.418} & \\
\hline & & & & & & & & 503.418 & & & & & & & \multirow[b]{3}{*}{35.703} \\
\hline & \multirow[b]{2}{*}{ OT } & & & & & & & 1.350 & 1.500 & 1.650 & 1.800 & 1.950 & 2.100 & \multirow{2}{*}{153.079} & \\
\hline & & & & & & & & 15.095 & & & 91.676 & 46.308 & & & \\
\hline \multirow{4}{*}{8} & \multirow[b]{2}{*}{ RT } & & & & & & & & 1.125 & 1.275 & 1.425 & 1.575 & 1.725 & \multirow{2}{*}{526.301} & \\
\hline & & & & & & & & & 526.301 & & & & & & \\
\hline & \multirow[b]{2}{*}{ OT } & & & & & & & & 1.350 & 1.500 & 1.650 & 1.800 & 1.950 & \multirow{2}{*}{197.363} & \\
\hline & & & & & & & & & 75.531 & & 121.832 & & & & \\
\hline \multirow{4}{*}{9} & \multirow{2}{*}{ RT } & & & & & & & & & 1.125 & 1.275 & 1.425 & 1.575 & \multirow{2}{*}{526.301} & \\
\hline & & & & & & & & & & 526.301 & & & & & \\
\hline & & & & & & & & & & 1.350 & 1.500 & 1.650 & 1.800 & \multirow{2}{*}{197.363} & \\
\hline & OT & & & & & & & & & 196.493 & 870 & & & & \\
\hline \multirow{4}{*}{10} & \multirow{2}{*}{ RT } & & & & & & & & & & 1.125 & 1.275 & 1.425 & \multirow{2}{*}{503.418} & \\
\hline & & & & & & & & & & & 503.418 & & & & \\
\hline & \multirow[b]{2}{*}{ OT } & & & & & & & & & & 1.350 & 1.500 & 1.650 & \multirow{2}{*}{188.782} & \\
\hline & & & & & & & & & & & 188.782 & & & & \\
\hline \multirow{4}{*}{11} & RT & & & & & & & & & & & 1.125 & 1.275 & \multirow{2}{*}{526.301} & \\
\hline & & & & & & & & & & & & 526.301 & & & \\
\hline & & & & & & & & & & & & $\begin{array}{l}1.350 \\
\end{array}$ & 1.500 & \multirow{2}{*}{197.363} & \\
\hline & OT & & & & & & & & & & & 197.363 & & & \\
\hline & & & & & & & & & & & & & 1.125 & 526301 & \\
\hline 12 & RT & & & & & & & & & & & & 526.301 & $J 20.101$ & \\
\hline 12 & & & & & & & & & & & & & 1.350 & 103232 & 94141 \\
\hline & OT & & & & & & & & & & & & 103.222 & 103.222 & $7+141$ \\
\hline & $\begin{array}{l}\text { Sebutuhan } \\
\text { Produlussi }\end{array}$ & 658.342 & 640.292 & 691.986 & 715.736 & 735.541 & 688.874 & 518.514 & 601.832 & 722.794 & 906.578 & 769.972 & 629.523 & & 502.112 \\
\hline
\end{tabular}

\section{Gambar 5. Lanjutan Matriks Perhitungan Metode Transportasi (Least cost)}

Pengalokasikan pada gambar diatas dilakukan dengan metode (least cost). Metode ini adalah pengalokasian yang memprioritaskan alokasi kapasitas produksi untuk memenuhi permintaan dengan biaya produksi yang paling murah terlebih dahulu. Jumlah Winker relay yang dapat dihasilkan dalam satu bulan dengan waktu produksi normal adalah sesuai dengan kapasitas produksi normal setiap bulannya. Jika kapasitas produksi secara normal masih belum cukup memenuhi permintaan, maka dilakukan dengan waktu produksi lembur dalam satu 
periode. Jika masih belum memenuhi juga, maka akan dialokasikan pada periode sebelumnya yang masih mempunyai sisa kapasitas lembur.

Berdasarkan hasil Pengalokasian tersebut, diperoleh biaya produksi Winker relay seperti dibawah ini :

Tabel 5. Perincian Total Biaya Produksi Metode Transportasi

\begin{tabular}{cccc}
\hline Periode & Biaya & Biaya OT & Biaya Simpan \\
\hline 1 & Rp. 566.345.751 & Rp. 209.146.933 & 0 \\
\hline 2 & Rp. 566.345.751 & Rp. 184.779.568 & 0 \\
\hline 3 & Rp. 617.831.729 & Rp. 208.842.515 & 0 \\
\hline 4 & Rp.566.345.751 & Rp. 254.855.588 & Rp.3.530.415 \\
\hline 5 & Rp. 592.088.740 & Rp.266.439.933 & Rp.3.563.119 \\
\hline 6 & Rp. 592.088.740 & Rp.219.473.250 & 0 \\
\hline 7 & Rp.566.345.751 & Rp.206.656.515 & 0 \\
\hline 8 & Rp. 592.088.740 & Rp.266.439.933 & 0 \\
\hline 9 & Rp.592.088.740 & Rp.266.570.844 & 0 \\
\hline 10 & Rp. 566.345.751 & Rp.254.855.588 & Rp.77.934.308 \\
\hline 11 & Rp. 592.088.740 & Rp.266.439.933 & Rp.27.784.527 \\
\hline 12 & Rp. 592.088.740 & Rp.139.350.048 & 0 \\
\hline Total & Rp.7.002.092.926 & Rp.2.743.850.650 & Rp.112.812.369 \\
\hline \multicolumn{5}{c}{ Rp.9.858.755.945 } \\
\hline
\end{tabular}

Berdasarkan pengolahan data diketahui secara terperinci besarnya total biaya produksi Winker relay yang dilakukan dalam waktu produksi normal dan waktu produksi lembur. Hasil perhitungan total biaya produksi Winker relay dari perencanaan agregat dengan metode transportasi adalah sebesar Rp9.858.775.945.

Tabel 6. Perbandingan hasil perencanaan agregat berdasarkan 3 metode

\begin{tabular}{|c|c|c|c|}
\hline Metode & $\begin{array}{l}\text { Transportasi } \\
\text { (Least cost) }\end{array}$ & $\begin{array}{l}\text { Tenaga kerja } \\
\text { tetap }\end{array}$ & Level strategy \\
\hline $\begin{array}{c}\text { Biaya } \\
\text { Regular time } \\
\text { (RT) }\end{array}$ & Rp7.002.092.926 & Rp7.002.092.926 & Rp7.002.092.926 \\
\hline $\begin{array}{l}\text { Biaya } \\
\text { Overtime } \\
(\mathrm{OT})\end{array}$ & Rp. 2.743.720.150 & Rp3.150.941.817 & Rp3.150.941.817 \\
\hline $\begin{array}{c}\text { Biaya } \\
\text { Simpan }\end{array}$ & Rp. 112.812.369 & - & $\mathrm{Rp} \quad 383.781 .114$ \\
\hline Total Biaya & Rp. 9.858.625.445 & Rp10.153.034.743 & Rp10.536.815.875 \\
\hline
\end{tabular}

Berdasarkan ketiga metode perencanaan agregat yang telah dilakukan maka metode perencanaan agregat yang terpilih adalah metode transportasi (least cost). Hal ini disebabkan karna metode transportasi menghasilkan total ongkos produksi paling kecil dibandingkan metode yang lainnya karena metode transportasi ini mengalokasikan jumlah yang diproduksi sesuai dengan kebutuhan produksi sehingga tidak terlalu banyak memiliki inventory yang tersisa untuk disimpan dan tidak terlalu banyak mengeluarkan biaya untuk overtime, metode transportasi ini menghasilkan total ongkos produksi sebesar Rp 9.858.775.945. 


\section{SIMPULAN}

Kesimpulan merupakan hasil dari pengolahan data yang telah dilakukan dalam perencanaan produksi agregat. Kesimpulan ini menjawab dari rumusan masalah yang telah dibuat. Adapun kesimpulan yang diperoleh dari hasil pembahasan tersebut antara lain :

1. Peramalan permintaan produk Winker relay yang dipilih adalah metode double exponential smooothing. Metode ini dipilih karena memiliki nilai kesalahan peramalan terkecil yakni dengan nilaiMAPE sebesar $2,7 \%$ Serta nilai Tracking signal yang bergerak dari $-3,10$ sampai dengan $+3,5$ dan hal ini berada didalam batas-batas yang dapat diterima (maksimum $\pm 4)$.

2. Perencanaan agregat produk Winker relay yang menghasilkan total ongkos produksi paling minimum adalah menggunakan metode transportasi (Least cost), dengan total biaya produksi yang dihasilkan sebesar $\mathrm{Rp}$ 9.858.775.945.Hasil persentase pencapaian produksi produk winker relay pada tahun 2017 jika menggunakan metode transportasi (Least cost) akan memiliki nilai sebesar 99,22\%, hasil ini artinya lebih tinggi tingkat pencapaian produksi disbanding dengan pencapaian pada tahun 2016 yang menggunakan metode menurut kebijakan perusahaan dengan nilai pencapaian sebesar 93,19\%.

\section{DAFTAR PUSTAKA}

Alfarisi, S. 2017. Sistem Prediksi Penjualan Gamis Toko Qitaz Menggunakan Metode Single Exponential Smoothing. Journal of Applied Business and Economics. 82-84.

Heizer, Jay dan Barry Render. 2015. Operations Management (Manajemen Operasi), ed.11, Penerjemah: Dwi anoegrah wati S dan Indra Almahdy, Salemba empat, Jakarta

Hudiyanti, C. V. 2019. Perbandingan Double Moving Average dan Double Exponential Smoothing untuk Peramalan Jumlah Kedatangan Wisatawan Mancanegara di Bandara Ngurah Rai. Jurnal Pengembangan Teknologi Informasi dan Ilmu Komputer, 2669.

Nasution, A. H. 2008. Perencanaan dan Pengendalian Produksi. Yogyakarta: Graha Ilmu.

Nurlifa, A. 2017. Sistem Peramalan Jumlah Penjualan MenggunakanMetode Moving Average Pada Rumah Jilbab Zaky. Jurnal Inovtek Polbeng. 20-21.

Perdana, F. R. 2014. Perbandingan Metode DES (Double Exponential Smoothing) dengan TES (Triple Exponential Smoothing) Pada Peramalan Penjualan Rokok (Studi Kasus Toko Utama Lumajang).

Rachman, R. 2018. Penerapan Metode Moving Average dan Exponential Smoothing pada Peramalan Produksi Industri Garment. Jurnal Informatika.213.

Renyaan, N. I. (2018). Perbandingan Metode Regresi Linier Dan Kuadratik Dalam Peramalan Penjualan Sepeda Motor. 6-7.

Schroeder, Roger G., Susan Meyer Goldstein, M. Johnny Rungtusanatham. 2013. Operation Management Contemporary Concepts and Cases, 6th edition. McGraw-Hill, New York

Tannady, H. 2013. Analisis Perbandingan Metode Regresi Linier Dan Exponential Smoothing Dalam Parameter Tingkat Error. Jurnal Teknik dan Ilmu Komputer .244. 